\title{
Effects of drugs on walking after spinal cord injury
}

\author{
Kathleen E Norman, André Pépin and Hugues Barbeau \\ School of Physical \& Occupational Therapy of McGill University, 3630 Drummond St., Montreal, Quebec, Canada \\ H3G $1 Y 5$
}

Clonidine, a noradrenergic agonist, and cyproheptadine, a serotonergic antagonist, have each been associated with improved walking in SCI subjects. Baclofen, a GABA agonist, is frequently prescribed for spasticity but its effects on walking have not been well quantified. The objective of this study was to compare the effects of clonidine, cyproheptadine and baclofen on walking in SCI subjects with incomplete injuries. A motorized treadmill was used and harness support provided when necessary. A repeated single-subject design was employed for the twelve subjects. The greatest effects were found in more severely disabled subjects. Cyproheptadine was associated with greatly reduced need for assistance, increases in maximum treadmill speed (MTS) and reduced clonus. Clonidine was associated with increases in MTS and a generally more upright posture. Baclofen was associated with minor changes in walking. In many cases of drug effects, MTS increases and other changes were retained following washout of drugs. The significance and implications of the drug effects and the retention of effects during washout periods are discussed. It is concluded that clonidine and cyproheptadine have different effects but both appear useful for severely disabled SCI subjects. The effects of baclofen on walking after spinal cord injury remains unclear.

Keywords: spinal cord injuries; gait; clonidine; cyproheptadine; baclofen

\section{Introduction}

The proportion of spinal cord injuries that are clinically incomplete now form the majority of spinalcord-injured (SCI) cases in many countries. ${ }^{1-6}$ However, the proportion of newly injured SCI patients who are capable of reciprocal gait by discharge from rehabilitation is smaller: approximately one-quarter to one-third. ${ }^{1,4}$ Moreover, many patients who are able to walk need assistive devices and do not use walking as their primary mode of locomotion. The rehabilitation of walking generally comprises strategies of strengthening available muscles and walking training with appropriate assistive devices. When drug therapy is included, the goal is often to reduce spasticity rather than to improve walking directly. Although the clinical signs of abnormal gait and spasticity are often associated with one another, the nature of their relationship is unclear. ${ }^{7-11}$ Many of the therapeutic strategies for spasticity are directed at neurotransmitter systems that have been shown in animal models to play a role in the modulation of locomotion.

Clonidine, a noradrenergic agonist, and cyproheptadine, a serotonergic antagonist, have both been studied for their effects on walking pattern in SCI humans. ${ }^{12-14}$ Clonidine did not affect locomotion in SCI subjects with functionally complete injuries, ${ }^{14,15}$

Correspondence: H Barbeau but was associated with improved walking in SCI subjects with incomplete injuries. ${ }^{14}$ Cyproheptadine has been associated with an improvement in walking pattern in subjects with spastic paresis. ${ }^{12,13}$ However, clonidine and cyproheptadine have not been compared to each other, and neither has been compared to other pharmacological treatment presently in use for SCI patients. Baclofen, a gamma aminobutyric acid (GABA)-ergic agonist, is a commonly used drug for spasticity in the SCI population. Baclofen treatment, oral or intrathecal, has been associated with improvements in some aspects of motor function ${ }^{16,17}$ but whether it has specific effects on recovery of walking has received little attention.

The purpose of the present study, therefore, was to compare the effects of clonidine, cyproheptadine and baclofen on the walking pattern of SCI subjects with chronic incomplete lesions. SCI subjects more than one year post-injury were recruited to participate, based on the observation that the majority of neurological recovery has taken place by the end of the first year. ${ }^{18,19} \mathrm{~A}$ repeated single-subject design was selected in order to maximize the number of subjects in whom the effects of the drugs could be studied. The inclusion criteria were broader for this exploratory study than would have been employed had this been a clinical trial in order to examine the drug effects in subjects with a wide range of disability from spinal 
cord injury. Preliminary results of this study have been reported previously. ${ }^{20-22}$

\section{Methods}

\section{Subjects}

Twelve subjects were recruited, based on the following inclusion criteria: incomplete spinal cord injury more than 1 year previously with motor sparing and hyperreflexia; no other major neurological or orthopedic diagnoses; and not taking any drug known or suspected to alter muscle tone, other than the drugs under study. All subjects were currently living in the community, independently or with family. They ranged in age from 19-35 years old and were free of other medical problems except as noted (see Table 1). All had sustained a traumatic spinal cord injury $1-6$ years prior to entering the study. All subjects were men; none of the women referred to the laboratory during the study recruitment period were eligible to participate. Almost all subjects had some experience with drugs for spasticity, and six were on current oral drug for spasticity at entry to the study. A description of the subjects can be found in Table 1. The information in Table 1, except for the determination of the neurological level of injury (NLI), was obtained from the referring physician as well as from the initial meeting with each subject to determine eligibility and willingness to participate. The NLI was obtained from a focussed clinical evaluation conducted by the experimenters based on the reported level of injury.

The protocol was approved by the university departmental ethics committee as well as by those of the rehabilitation institutions from which subjects were referred. All subjects confirmed in writing their informed consent to participate.

Four of the 12 subjects were incapable of walking at entry to the study and required the support of the harness system ${ }^{23,24}$ in order to be evaluated. They have been coded $\mathrm{H} 1, \mathrm{H} 2, \mathrm{H} 3$ and $\mathrm{H} 4$. The other eight subjects were able to walk at entry to the study, although six of those eight continued to use a wheelchair as the primary mode of locomotion. These six subjects have been coded according to the aids used for walking overground: W indicates that a fourpoint walker was used; $\mathrm{P}$ indicates that another person was required for minimal assistance; and $\mathrm{C}$ indicates that two forearm crutches were used. These six subjects were coded $\mathrm{W} 1, \mathrm{~W} 2, \mathrm{P} 1, \mathrm{C} 1, \mathrm{C} 2$ and $\mathrm{C} 3$. The other two subjects had discontinued any use of a wheelchair and have been coded S1 and S2 because both used a single aid (cane or crutch) for walking overground.

\section{Drugs}

All drugs were tablets to be taken orally. A schematic version of the protocol can be found in Figure 1. For each drug there was a stage of increasing dosage followed by a stage of stable dosage, then a stage of tapering dosage, and finally a stage of no drug (washout). The stages of increasing dosage and stable dosage together took three weeks, and the tapering stage and washout together took two weeks. The maximum total daily doses were as follows: baclofen $80 \mathrm{mg}$, clonidine $0.25 \mathrm{mg}$, and cyproheptadine $24 \mathrm{mg}$. Since clonidine can have a hypotensive effect, each subject was followed by a nurse in his home community during the period of increasing dosage of clonidine for side effects that might suggest hypotension. Measurement of blood pressure was performed where symptoms indicated.

Since this was intended as an exploratory study, decisions regarding drug dosage, order and duration of drug period were taken with the intent of maximizing the subjects' motivation to continue in the study and minimizing the time that it took for each subject to complete the study. Thus, subjects who were referred while taking one of the three study drugs were evaluated first without any change in their drug $(\mathrm{H} 1$, W2, C1, C3, S1: baclofen; C2: clonidine). Subjects were not blind to drug identity. However, the consent form listed the possible effects of the drugs together to minimize the effect of expectation.

\section{Evaluations}

Timing and procedure for evaluations Each subject was evaluated one to four times at entry to the study, then after the period of stable dosage of each drug, and after each washout period (see Figure 1). At each visit to the laboratory, subjects were interviewed for their impressions of beneficial effects and side effects associated with the current drug or washout.

The instrumented gait evaluation yielded electromyographic (EMG) and kinematic data. One side of the subject was evaluated in greater detail. It was the side that seemed to be more spastic during a clinical evaluation on the first visit. If both sides were essentially equal, the choice was based on practical considerations (eg the usual location of a urinary collection bag, if present).

Surface electrodes were taped to the skin over the bellies of selected lower limb muscles: ipsilateral tibialis anterior (TA); soleus (SO); medial belly of gastrocnemius (GA); vastus lateralis (VL); and the medial hamstrings $(\mathrm{MH})$. Each electrode set had a built-in differential pre-amplifier with a gain of 10 . The signals were fed via a common cable to amplifiers in which there was a bandpass filter $(10-1000 \mathrm{~Hz})$ and a notch filter $(60 \mathrm{~Hz})$ and a further gain. The signals were then recorded on FM tape. The total gain of the EMG signals on tape was 1000 or $2000 \mathrm{X}$, depending on the amplitude of the signal.

Pressure-sensitive switches were taped to the soles of the subject's shoes: under the centre of the heel, under the head of the fifth metatarsal, and under the great toe. The foot-switch records were recorded on FM tape simultaneously with the EMG signals. During 
Table 1 Subject characteristics ${ }^{\mathrm{a}}$

\begin{tabular}{|c|c|c|c|c|c|c|c|c|c|c|}
\hline & $\begin{array}{l}\text { Age at } \\
\text { entry }\end{array}$ & $\begin{array}{c}\text { Years since } \\
\text { injury } \\
\text { at entry }\end{array}$ & N.L.I. & $\begin{array}{l}\text { Activity when } \\
\text { injury occured }\end{array}$ & $\begin{array}{l}\text { Primary mode } \\
\text { of locomotion } \\
\text { at entry }\end{array}$ & $\begin{array}{l}\text { Able to rise } \\
\text { from sitting? }\end{array}$ & $\begin{array}{c}\text { Able to } \\
\text { maintain standing? }\end{array}$ & $\begin{array}{l}\text { Able to walk on } \\
\text { level surfaces? }\end{array}$ & $\begin{array}{c}\text { Past } \\
\text { experience with } \\
\text { antispastic drugs }\end{array}$ & $\begin{array}{l}\text { Drugs at } \\
\text { entry }\end{array}$ \\
\hline $\mathrm{H} 1$ & 32 & 1.2 & $\mathrm{C} 5$ & diving & manual wheelchair & with help & $\begin{array}{l}\text { with forearm } \\
\text { support walker }\end{array}$ & No & baclofen & baclofen \\
\hline $\mathrm{H} 2$ & 27 & 1.6 & T11 & $\begin{array}{l}\text { all-terrain } \\
\text { vehicle riding }\end{array}$ & manual wheelchair & with walker & with walker & $\begin{array}{l}\text { Limited swing-to } \\
\text { with walker }\end{array}$ & $\begin{array}{l}\text { diazepam, } \\
\text { baclofen }\end{array}$ & none \\
\hline H3 & 33 & 2.3 & C6 & diving & manual wheelchair & No & No & No & $\begin{array}{l}\text { clonidine, } \\
\text { baclofen, } \\
\text { diazepam }\end{array}$ & none \\
\hline H4 & 23 & 5.3 & $\mathrm{C} 5$ & diving & manual wheelchair & No & No & No & clonidine, & none \\
\hline W1 & 29 & 3.5 & C6 & fall & manula wheelchair & with walker & with walker & $\begin{array}{l}\text { with walker, } \\
\text { supervision }\end{array}$ & $\begin{array}{c}\text { diazepam } \\
\text { none }^{3}\end{array}$ & none $^{3}$ \\
\hline W2 & 35 & 4.8 & C6 & fall & manula wheelchair & with walker & with walker & with walker & baclofen & baclofen $^{4}$ \\
\hline P1 & 30 & 2.3 & $\mathrm{C} 4$ & diving & $\begin{array}{c}\text { manual or } \\
\text { motorized }^{5} \\
\text { wheelchair }^{\text {nar }}\end{array}$ & with supervision & with supervision & $\begin{array}{l}\text { with supervision, } \\
\text { assistance }^{5}\end{array}$ & baclofen & none \\
\hline $\mathrm{C} 1$ & 19 & 1.1 & $\mathrm{C} 7$ & riding in car & manual wheelchair & $\begin{array}{l}\text { with forearm } \\
\text { crutches }\end{array}$ & $\begin{array}{l}\text { with forearm } \\
\text { crutches }\end{array}$ & $\begin{array}{l}\text { with forearm } \\
\text { crutches }\end{array}$ & baclofen & baclofen \\
\hline $\mathrm{C} 2$ & 28 & 1.3 & C6 & diving & manual wheelchair & $\begin{array}{l}\text { with forearm } \\
\text { crutches }\end{array}$ & $\begin{array}{l}\text { with forearm } \\
\text { crutches }\end{array}$ & $\begin{array}{l}\text { with forearm } \\
\text { crutches }\end{array}$ & clonidine & clonidine \\
\hline $\mathrm{C} 3$ & 22 & 2.2 & $\mathrm{~T} 12$ & $\begin{array}{l}\text { motorcycle } \\
\text { riding }\end{array}$ & manual wheelchair & $\begin{array}{l}\text { with forearm } \\
\text { crutches }\end{array}$ & $\begin{array}{l}\text { with forearm } \\
\text { crutches }\end{array}$ & $\begin{array}{l}\text { with forearm } \\
\text { crutches }\end{array}$ & baclofen & baclofen \\
\hline $\mathrm{S} 1$ & 20 & 4.9 & C6 & riding in car & $\begin{array}{l}\text { walking with } \\
\text { straight cane }\end{array}$ & $\begin{array}{l}\text { Without help } \\
\text { or aid }\end{array}$ & $\begin{array}{l}\text { Without help } \\
\text { or aid }\end{array}$ & $\begin{array}{c}\text { Without help } \\
\text { or aid }\end{array}$ & baclofen $^{6}$ & baclofen \\
\hline $\mathrm{S} 2$ & 19 & 2.8 & C6 & diving & $\begin{array}{l}\text { walking with } \\
1 \text { forearm crutch }\end{array}$ & $\begin{array}{l}\text { Without help } \\
\text { or aid }\end{array}$ & $\begin{array}{l}\text { Without help } \\
\text { or aid }\end{array}$ & $\begin{array}{l}\text { with forearm } \\
\text { crutch }\end{array}$ & baclofen & none \\
\hline
\end{tabular}

${ }^{a}$ Within the Frankel (1969) classification, subjects $\mathrm{H} 1-\mathrm{H} 4$ would be considered in category C: sparing of both sensory and motor function where the motor function is not functional. They were not evaluated according to the newer A.S.I.A./I.M.S.O.P. protocol (1992), but would almost certainly all be in category C. Subjects W1, W2, P1 and $\mathrm{C} 1-\mathrm{C} 3$ would be considered in category D of the Frankel classification: sparing of both sensory and motor function where the motor function is functional. If they had been evaluated according to the A.S.I.A./I.M.S.O.P. protocol, some would likely be in category C and others in category D. Subjects S1 and S2 would be considered in category D of the Frankel scale: sparing of both sensory and motor funtion where the motor function is funtional. Although they were not evaluated according to the A.S.I.A./I.M.S.O.P. protocol, both would likely be in category D. ${ }^{b}$ N.L.I. = neurological level of $i$ jury (A.S.I.A./I.M.S.O.P. (1992) classification system; lowest spinal level with normal sensory and motor function). ${ }^{\mathrm{C}} \mathrm{W} 1 \mathrm{had}$ a lifelong history of epilepsy and was taking anticonvulsant medication (divalproex sodium: Epival ${ }^{\mathrm{R}}$ ). He had also been taking an antidepressant (imipramine: Tofranil ${ }^{\mathbb{R}}$ ) since his injury. Both medications were held at stable dosage throughout his participation in the study. ${ }^{\mathrm{d}} \mathrm{W} 2$ had previously been prescribed an anxiolytic (bromazepam: Lectopam ${ }^{\mathbb{R}}$ ) which he took occasionally to help him sleep. He reported that his pattern of usage of this medication did not change over the course of his participation in the study. ${ }^{\mathrm{e}} \mathrm{P} 1$ generally used a motorized wheelchair when outdoors, and a manual wheelchair when indoors. He propelled the latter with his feet. ${ }^{\mathrm{f}} \mathrm{S} 1 \mathrm{had}$ received surgical treatments for spasticity in addition to the medication. He had undergone partial neurectomies for right gastrocnemius spasticity and right adductor spasticity. The surgeries took place 21 months and nine monthes, respectively, prior to entry to the study 


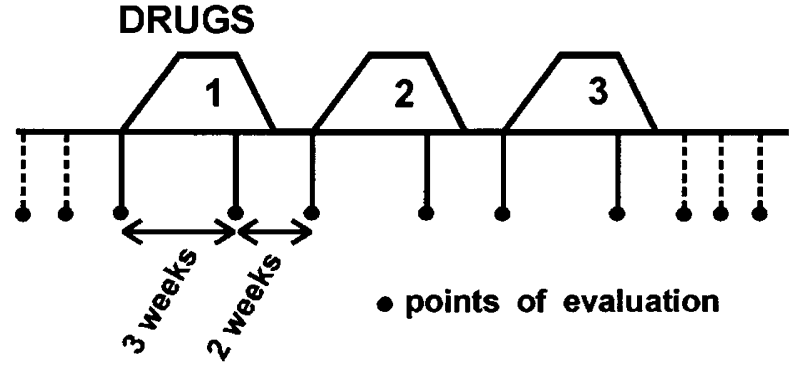

Figure 1 The study protocol is illustrated. Evaluations were conducted at the beginning of each drug period, at the end of a period of stable dosage, and at the end of each washout. Additional evaluations before any drugs, and after all three drugs were conducted where possible. The time from starting a drug to the evaluation for that drug was at least three weeks, and the washout period was at least 2 weeks

subsequent off-line analysis, the tape was replayed and signals were sent to a computer via an analog-todigital convertor (12-bit, dynamic range $\pm 10 \mathrm{~V}$ ) with sampling of the signals at 1000 or $1200 \mathrm{~Hz}$. Footswitch signals were inspected visually to determine gait cycle boundaries.

Kinematic data was obtained from digitization of videotaped recordings using standard VHS tapes with a sampling rate of 60 fields per second. For visualization of joint positions, reflective markers were attached to the subject over the following anatomical landmarks: head of the fifth metatarsal, lateral aspect of the calcaneus, lateral malleolus, lateral joint line of the knee, greater trochanter of the femur, and greater tubercle of the humerus. Angular data are reported using standard biomechanical convention: hip at $0^{\circ}$ represents neutral position $\left(0^{\circ}\right.$ flexion, $0^{\circ}$ extension $)$, knee at $0^{\circ}$ represents full extension, ankle at $0^{\circ}$ represents neutral position (shank and foot segments at $90^{\circ}$ to one another). Digitization of video records was performed off-line using computer software (Peak Performance Technologies Inc., Englewood, CO, USA). Automatic digitization was performed when possible, supplemented by manual digitization when required.

Four of the 12 subjects (H1-4) required harness support to be evaluated on the treadmill. The harness has been more fully described elsewhere. ${ }^{24}$ Essentially, it allows for the support of body weight via a pulley system over the treadmill. Although it has been recognized that support levels above $50 \%$ of body weight are associated with abnormalities in walking patterns, ${ }^{25}$ some subjects were incapable of producing any reciprocal leg movements unless greater support was provided. Support provided by the harness varied from $10-90 \%$ body weight support (BWS) depending upon the subject's posture and the extent to which he gained support from the parallel bars on the treadmill. Treadmill belt motion was started from a full stop, and increased slowly until the subject reported that it was at a comfortable speed for him to continue stepping. Subjects were assisted, if appropriate, in the movement of their legs by experimenters positioned adjacent to the treadmill. The assistance continued in the first evaluation for as long as the subject required it, and was repeated at any subsequent evaluation in which the subject was unable to perform stepping independently. If the subject was capable of taking steps independently, the treadmill belt movement was set at the speed at which he could best sustain continuous stepping. If the subject required assistance, the treadmill speed was generally 0.03 to $0.05 \mathrm{~m} \cdot \mathrm{s}^{-1}$, depending upon the experimenters' difficulty in moving the subjects' legs. In such situations, however, a subject's maximal treadmill speed was classified as $0.0 \mathrm{~m} \cdot \mathrm{s}^{-1}$, reflecting his inability to follow the treadmill unassisted. During each trial the treadmill belt movement continued at a steady speed for as long as the subject could continue to follow it without needing a rest, generally several minutes at a time. Rest periods were at least as long as walking trials, and generally several minutes longer. After several trials at the reported comfortable speed, trials were attempted at higher speeds if the subject could manage them. Before each successive trial, the harness height and attachments were adjusted if necessary for optimal performance of stepping.

For the other eight subjects, treadmill walking was evaluated without harness support. All subjects used the parallel bars on the treadmill as much as they wished. As with the harness-using subjects, the treadmill belt motion was started from a full stop, and increased slowly. For the slower subjects, a comfortable speed was reached quickly, generally $\leqslant 0.10 \mathrm{~m} \cdot \mathrm{s}^{-1}$. For the subjects whose walking capacity was less limited, a longer habituation period of several minutes' duration was provided, so that subsequent decisions regarding comfortable and maximal speeds could be more certain.

For all subjects at each of their evaluations, trials were performed at the reported comfortable speed, as well as at higher speeds. When the comfortable speed at a given evaluation was higher than at previous evaluations, trials were performed at previously comfortable speeds to allow better comparison across evaluations. The subject rested for several minutes as needed between trials. The speed was re-increased slowly for re-starting the walking trials. For the trials at speeds exceeding the comfortable speed, the treadmill speed was increased by intervals of $0.05 \mathrm{~m} \cdot \mathrm{s}^{-1}$ (for slower subjects) or $0.10 \mathrm{~m} \cdot \mathrm{s}^{-1}$ until the subject was unable to complete a trial at a given speed, or he indicated that he did not wish to continue. A subject's maximal treadmill speed was considered the highest speed at which he could manage to continue walking for at least 10 gait cycles or one minute, whichever was shorter.

Data analysis As this was an exploratory study, the results are presented descriptively, so as to demonstrate the range of responses to the drugs, mostly varying 
with the severity of disability from spinal cord injury. The heterogeneity of the subjects' disability as well as of their responses to drugs prevented the collapsing of data for inferential statistics. Despite the heterogeneity, however, there were some similarities among the responses to drugs and these are described below.

For the analysis of walking speed, the data are presented in the sequence of changes in speed (Figures 2 and 5) as well as in a more integrated form for comparison of drug effect (Figure 8). For the analysis of walking pattern, the EMG and kinematic data are presented in raw form when only a limited number of cycles were available (Figures 3 and 4). Where EMG averaging was performed (eg Figure 6), the data were first bandpass filtered $(20-500 \mathrm{~Hz})$, full-wave rectified, smoothed with a moving window average, and normalized in time across stance and swing phases separately. Where kinematic averaging was performed (eg Figure 7), the data were first normalized in time across stance and swing phases separately.

\section{Results}

Completion of the protocol by subjects

Seven of the 12 subjects were able to undergo evaluations in association with all of the three drugs.

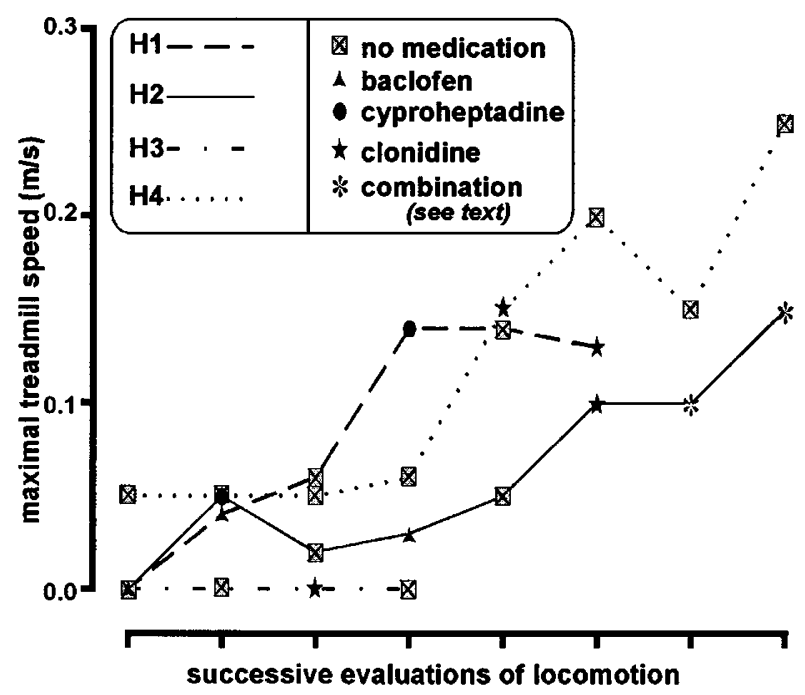

Figure 2 Maximal treadmill speed (MTS) over successive evaluations of locomotion in $\mathrm{H} 1, \mathrm{H} 2, \mathrm{H} 3$ and $\mathrm{H} 4$. In all cases, the MTS was evaluated at whatever harness support level was optimal for highest speed. The initial zero values for $\mathrm{H} 1$ and $\mathrm{H} 2$ reflect the fact that neither could sustain stepping without manual assistance for at least $1 \mathrm{~min}$. Zero values for all evaluations for $\mathrm{H} 3$ reflect the fact that he was unable at any evaluation to perform stepping without manual assistance. (See Results section text for further explanation of how MTS was ascertained.) Drug status is reflected by the symbols as indicated in the legend. Each subject's values are linked by a different type of line (see legend).

(Reprinted with the permission of Williams and Wilkins)
For four of the other five subjects, adverse effects prevented the completion of one or more of the evaluations for drug effects. The adverse effects are summarized in Table 2, and will be discussed in a subsequent section. One subject (H3) dropped out for personal reasons.

\section{Subjects with no overground reciprocal walking}

The most striking results were seen in the subjects who were incapable of overground walking at entry to the study. For all four of the subjects in this group, their changes in maximal treadmill speed (MTS) are shown in Figure 2.

All four of the subjects required manual assistance during every step cycle in their first attempt at harnesssupported stepping on the treadmill. By the end of his initial evaluation, $\mathrm{H} 1$ had performed a few unassisted step cycles but never two consecutive cycles. H2 and H3 remained dependent for continuous manual assistance throughout their respective initial evaluations. For $\mathrm{H} 1, \mathrm{H} 2$ and $\mathrm{H} 3$, their initial MTS was therefore rated as $0.0 \mathrm{~m} \cdot \mathrm{s}^{-1}$. In contrast to the other three subjects, $\mathrm{H} 4$ was able, after several sequences with assistance, to perform stepping without manual assistance in his first evaluation at a MTS of $0.05 \mathrm{~m} \cdot \mathrm{s}^{-1}$. The MTS for $\mathrm{H} 1$ and $\mathrm{H} 2$ were rated above zero when they were able to perform at least one sequence with multiple consecutive step cycles without manual assistance, resulting in at least one minute of unassisted stepping. $\mathrm{H} 3$ continued to require manual assistance for every cycle throughout all of his evaluations.

Over successive drug and washout evaluations, three subjects $(\mathrm{H} 1, \mathrm{H} 2$ and $\mathrm{H} 4)$ showed changes in MTS. Cyproheptadine was associated with an increase in MTS from the immediately previous evaluation in two subjects $\left(\mathrm{H} 1: \quad 0.06 \mathrm{~m} \cdot \mathrm{s}^{-1}\right.$ to $0.14 \mathrm{~m} \cdot \mathrm{s}^{-1} ; \quad \mathrm{H} 2$ : $0.00 \mathrm{~m} \cdot \mathrm{s}^{-1}$ to $\left.0.05 \mathrm{~m} \cdot \mathrm{s}^{-1}\right)$. Clonidine was associated with an increase in two subjects $\left(\mathrm{H} 2: 0.05 \mathrm{~m} \cdot \mathrm{s}^{-1}\right.$ to $0.10 \mathrm{~m} \cdot \mathrm{s}^{-1} ; \quad \mathrm{H} 4: \quad 0.06 \mathrm{~m} \cdot \mathrm{s}^{-1}$ to $\left.0.15 \mathrm{~m} \cdot \mathrm{s}^{-1}\right)$. To illustrate the extent of the changes that could be observed, kinematic, EMG and temporal data from the series of evaluations are illustrated in Figures 3 and 4 for one subject (H1) who was able to complete all three drug periods. The extent to which other subjects showed similar changes is discussed below.

Figure 3 shows kinematic data and Figure 4 shows temporal and EMG data from evaluations of $\mathrm{H} 1$. The stance-swing transition is indicated in these illustrations and is later in the cycle than is usually reported for human gait but represents an average value for $\mathrm{H} 1$. It is important to note that there is a generally inverse relationship between the gait speed and the proportion of the cycle taken up by stance phase. ${ }^{26}$

During the first of H1's evaluations for baclofen, he required manual assistance from the experimenters to move his legs on the treadmill, despite the support provided by the harness $(20-40 \%$ BWS $)$ and his use of the parallel bars. A few times, he was able to 
perform a single cycle without manual assistance from the experimenters at $0.04 \mathrm{~m} \cdot \mathrm{s}^{-1}$. The hip, knee and ankle excursions from a single unassisted cycle are illustrated in solid lines in Figure 3a, b and c. The data are also shown in Figure 3d, illustrating the flexed posture that results from the flexion. Both the hip and the knee remain in flexion throughout the cycle, as is often seen when the BWS level is in or above the range of $20-40 \%$. In addition, his ankle remains in dorsiflexion throughout most of stance, also reflecting the flexed posture (see Figure 3c) until he attempts to bring his foot forward resulting in large oscillations of ankle dorsiflexion and plantarflexion (see arrows in Figure $3 \mathrm{c}$ and $\mathrm{d}$ ).

The changes seen in the kinematic records are paralleled by changes seen in the EMG records seen in

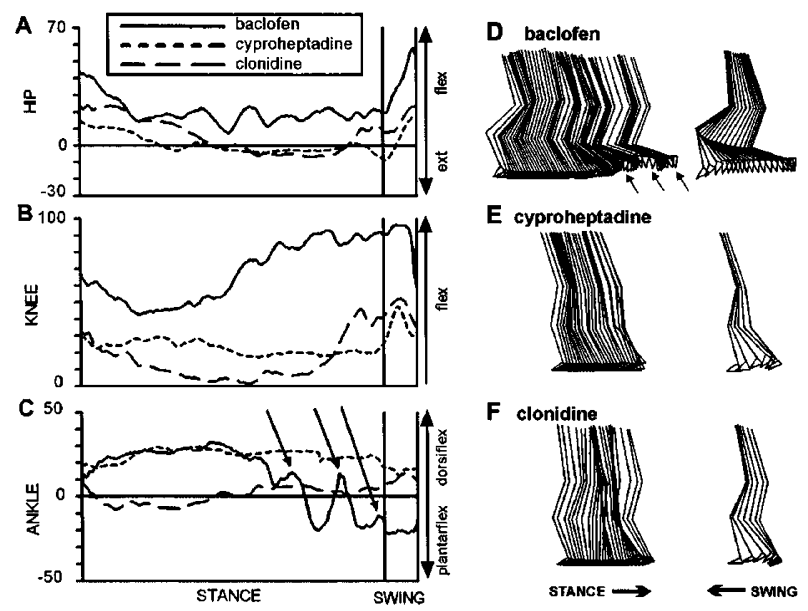

Figure 3 Normalized angular excursions of the left hip (a), knee (b) and ankle (c) of H1 during a cycle of treadmill stepping with harness support for each of baclofen (solid line, $0.04 \mathrm{~m} / \mathrm{s}$ ), cyproheptadine (dotted line, $0.06 \mathrm{~m} / \mathrm{s}$ ) and clonidine (dashed line, $0.06 \mathrm{~m} / \mathrm{s}$ ) evaluations. In order to align the stance-swing transition from all displayed cycles, a stance proportion of $90 \%$ was chosen as being representative of all cycles. Arrows in the ankle excursion (c) in late stance phase indicate oscillations occurring during efforts to initiate forward movement of the foot, accomplished in the swing phase by dragging it along the treadmill belt. Stick figure representations reconstructed from kinematic data for cycles during treadmill stepping in baclofen (d), cyproheptadine (e) and clonidine (f) evaluations. For stance phase, every tenth sample is illustrated such that between successive stick figures the time lapse is $0.167 \mathrm{~s}$; for swing phase, every fifth sample is illustrated such that between successive stick figures the time lapse is $0.083 \mathrm{~s}$. For the composite representations, the horizontal distance between stick figures was increased by $0.002 \mathrm{~m}$ over the distance actually moved (in direction of horizontal arrow) in order to improve the visibility of posture and joint angle excursions. The false impression of a long step length and a large backward translation of the trunk during stance is an artifact and should be disregarded. The diagonal arrows in $\mathbf{d}$ correspond to the ankle oscillations indicated by diagonal arrows in c
Figure 4a. These EMG signals were obtained in the second baclofen evaluation. H1 still required manual assistance for most stepping, the longest interval of unassisted stepping being five cycles at $0.04 \mathrm{~m} \cdot \mathrm{s}^{-1}$. The temporal data from these five cycles are shown in Figure 4a immediately above the raw EMG signals from three of these cycles. There was irregular activity of soleus throughout the cycle, with clonus in the third cycle accompanied by coactivation of tibialis anterior. The clonus is visible in the soleus by its characteristic $5-7 \mathrm{~Hz}$ bursting pattern. The vastus lateralis record shows little cyclical modulation in activity. The medial hamstrings record shows some cyclical modulation with activity primarily during single limb support, in contrast to the usual pattern of activity for the hamstrings in which it is active mostly in double limb support prior to single limb support on the ipsilateral side. ${ }^{27}$

In the post-baclofen washout evaluation, H1 showed minor changes in kinematic patterns although more striking changes in EMG patterns (Figure 4b). Furthermore, he had become capable of nine consecutive unassisted cycles, up from five in the previous evaluation. The hip and ankle excursions show little change except for reduced hip flexion and ankle plantarflexion in the latter part of the cycle. There is dorsiflexion in swing phase of the washout evaluation that was not present in the evaluation for baclofen. The knee excursions are also similar in profile, although there was a substantial reduction in flexion in late stance and swing in the washout evaluation as compared to the baclofen evaluation. In Figure $4 \mathrm{~b}$, it can be seen that the cycle durations remain long and the muscle activity is generally higher than in the previous evaluation. In particular, there is greater evidence of ankle clonus in the soleus, visible in late stance in the first cycle, and in early and midstance in the second cycle, with a burst of tibialis anterior activity frequently in coactivation with soleus. There is also prolonged, high-amplitude activity in the medial hamstrings.

During his cyproheptadine evaluation, $\mathrm{H} 1$ was able to follow the treadmill for several minutes without assistance and with $20-40 \%$ BWS at a speed of $0.06 \mathrm{~m} \cdot \mathrm{s}^{-1}$, and for at least a minute at $0.14 \mathrm{~m} \cdot \mathrm{s}^{-1}$ with similar BWS. The kinematic records from one cycle at $0.06 \mathrm{~m} \cdot \mathrm{s}^{-1}$ are illustrated in the dotted lines in Figure $3 \mathrm{a}-\mathrm{c}$ and in the stick figure representations in Figure $3 \mathrm{e}$. He achieved a more upright posture, as seen in the near $-0^{\circ}$ hip angle and in the reduced knee flexion in stance phase. The knee and hip also show a more coordinated flexion pattern during swing phase: both joints moved rapidly into flexion in early swing, and the knee moved back toward extension in late swing before the next foot contact. H1 also reduced the foot dragging that had been present in the baclofen evaluation. Abnormalities persist, however, in that the ankle remains dorsiflexed past neutral throughout stance phase, and he still required harness support for approximately the same BWS. Figure 4c shows 

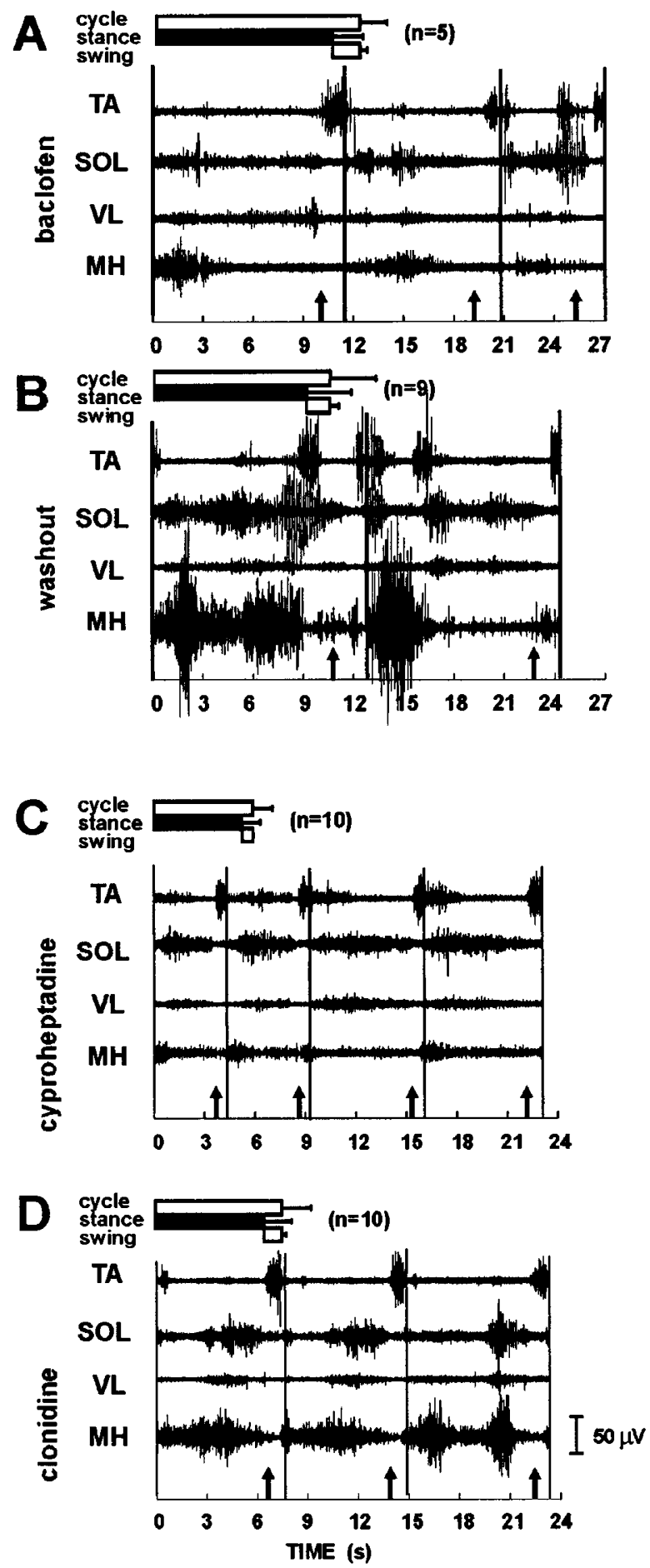

Figure 4 Average temporal durations and raw EMG signals from the left leg of $\mathrm{H} 1$ during treadmill stepping with harness support. Bars at top of each of $\mathbf{a}, \mathbf{b}, \mathbf{c}$ and $\mathbf{d}$ indicate temporal data. EMG records are shown below each set of bars. Upper unshaded bar indicates cycle duration, middle shaded bar indicates stance duration and lower unshaded bar indicates swing duration. Error bars indicate standard deviation, the number of cycles averaged is in parentheses. $\mathrm{TA}=$ tibialis anterior; $\mathrm{SO}=$ soleus; $\mathrm{VL}=$ vastus lateralis; $\mathrm{MH}=$ medial hamstrings. Vertical lines indicate cycle temporal and EMG data from this evaluation. In marked contrast to the evaluation for the previous (post-baclofen) washout, HI showed a regular pattern of muscle activity with cyproheptadine (Figure 4c). The soleus and tibialis anterior show a much more reciprocal pattern than previously seen. The soleus activity usually begins in early stance and diminishes in late stance at which point the tibialis anterior activity begins for its sharpest peak during the cycle. There is also some tibialis anterior activity seen in early stance, as is normal for weight acceptance. In addition, there is both a disappearance of clonus in soleus and a reduction in the prolonged highamplitude EMG activity in the medial hamstrings.

In the post-cyproheptadine washout evaluation, H1 showed a retention of many of the kinematic patterns seen in the cyproheptadine evaluation with three notable differences. First, there is less extension at the hip and knee in early stance of the washout evaluation. Second, there is a decrease in ankle dorsiflexion in mid-stance. Third, the flexion at the hip and knee in early swing in the cyproheptadine evaluation is absent in the washout evaluation, replaced by an earlier flexion of both joints that begins well before swing phase. Although some of the improvements seen in the cyproheptadine period disappeared in the washout period, the pattern did not revert to that seen in the washout evaluation that preceded cyproheptadine (ie the post-baclofen washout). In particular, the hip and knee remained less flexed in the post-cyproheptadine washout evaluation than in the washout evaluation that preceded cyproheptadine. The EMG records (not illustrated) reflected that H1's walking pattern only partly reverted to its state before cyproheptadine. The abnormal timing seen in the post-baclofen washout did not return, but clonus in soleus did return.

During the clonidine evaluation, $\mathrm{H} 1$ remained similarly capable of independent gait cycles with $20-$ $40 \% \mathrm{BWS}$, and the kinematic records from one cycle at $0.06 \mathrm{~m} \cdot \mathrm{s}^{-1}$ are illustrated in the dashed lines in Figure $3 \mathrm{a}-\mathrm{c}$ and the stick figure representations in Figure $3 \mathrm{f}$. There is little change in the hip angular excursion, in comparison with the cyproheptadine data, with a near-zero hip angle in stance reflecting an upright posture. The knee and ankle, however, show more noticeable differences. With clonidine, the knee remains in greater extension during stance phase and begins flexion earlier with respect to swing phase. The ankle remained near $0^{\circ}$ during stance, associated

boundaries (beginning of ipsilateral foot contact with the treadmill belt). Upward arrows at baseline indicate stanceswing transition. (a) Second evaluation while taking baclofen. (Note that clonus is most visible in soleus from time $=24 \mathrm{~s}$ to time $=26 \mathrm{~s}$.) (b) Evaluation at the conclusion of washout period after baclofen. (c) Evaluation during cyproheptadine period. (d) Evaluation during clonidine period 
with his more upright posture in this evaluation. A comparison of the kinematic data from the previous washout with those of the clonidine evaluation showed that the hip extension, knee extension and relative absence of ankle dorsiflexion are new changes with clonidine and had not been seen previously. In the stick figure representations in Figure $3 f$, the relative extension of the hip and knee are reflected in the more vertical orientation of the thigh and lower leg segments in the mid- to late stance phase.

Temporal and EMG data from a sequence at $0.06 \mathrm{~m} \cdot \mathrm{s}^{-1}$ during $\mathrm{H} 1$ 's clonidine evaluation are shown in Figure 4d. Although there was a return of evidence of ankle clonus (most evident in the third cycle), the soleus also showed relatively greater activity in mid- to late stance in a reciprocal pattern with the tibialis anterior, reflecting a more normal recruitment pattern. The medial hamstrings record, however, showed a partial return of the prolonged, highamplitude activation pattern that had been seen in washout evaluations.

In summary, $\mathrm{H} 1$ showed changes in walking ability at each drug and washout evaluation. From the baclofen evaluations to the subsequent washout evaluation, he showed a large increase in EMG activity and minor changes in kinematic pattern, including an increased dorsiflexion in swing phase. The greatest increase in stepping control and capacity was seen in the evaluation for cyproheptadine. Specifically, cyproheptadine was associated with a large increase in MTS, a more normal EMG pattern, reduced ankle clonus, a less flexed posture, and no further need for manual assistance with much longer sequences of stepping possible. Many of these improvements were retained in the subsequent washout period, although a slight deterioration can be seen in the kinematic pattern leading to a return to a more flexed posture. Clonidine was associated with a further improvement over the cyproheptadine period in the reciprocal activation of tibalis anterior and soleus, as well as in the less flexed posture.

The results for $\mathrm{H} 2$ were similar to those for $\mathrm{H} 1$ in that both cyproheptadine and clonidine were associated with marked changes in kinematic patterns and in MTS. Cyproheptadine was associated with a transformation from a posture with rigidly extended lower limbs requiring extensive manual assistance for even a few small steps to a state of independent stepping with only mechanical BWS for several minutes at a time. Following washout of cyproheptadine, $\mathrm{H} 2$ remained able to perform independent stepping, but with an altered kinematic pattern with more clonus and for more limited periods. The sequences of independent stepping in these evaluations were terminated when his posture reverted involuntarily to that of rigid extension and adduction of the lower limbs, an effect that had not been seen in the evaluation for cyproheptadine. During the subsequent baclofen period, his pattern remained similar to that during the previous (ie post-cyproheptadine) washout. Again, during the post-baclofen washout, there was essentially no change in his pattern. He showed minor increases in MTS across these evaluations. Subsequently, clonidine was associated with more important changes in his abilities. H2 doubled his MTS in the stepping sequences with his hips and knees flexed, similar to the posture of his previous independent sequences (see Figure 2, bold solid line). $\mathrm{He}$ also began to show signs of becoming independent at a stepping pattern with the hip and knee near extension in stance phase, performing only two cycles independently.

At the conclusion of the clonidine period, $\mathrm{H} 2$ elected to try a combination of clonidine and cyproheptadine. Cyproheptadine alone had permitted him to be relatively free of clonus and greatly reduced the 'scissoring' and strong extension, whereas clonidine had permitted him his first independent steps with support almost exclusively from the parallel bars. Although this period of combined cyproheptadine and clonidine did not form part of the experimental protocol, the results were evaluated and are reported here because of the changes that were seen. H2 continued to be capable of stepping in a flexed, harness-supported position at a MTS of $0.10 \mathrm{~m} \cdot \mathrm{s}^{-1}$ (see Figure 2, bold solid line). More importantly, he also became capable of independent stepping in an upright position with the harness system registering little support $(<10 \%$ BWS $)$ whereas previously he had always required manual assistance to move his legs in this extended, adducted posture. He maintained this pattern at a treadmill speed of $0.05 \mathrm{~m} \cdot \mathrm{s}^{-1}$ without assistance for sequences of at least a minute at a time. In a subsequent evaluation while still taking a combination of clonidine and cyproheptadine, he continued to increase his MTS at stepping in a flexed position to $0.15 \mathrm{~m} \cdot \mathrm{s}^{-1}$ (see Figure 2, bold solid line). His maximal speed for upright stepping, still without manual assistance, rose to $0.07 \mathrm{~m} \cdot \mathrm{s}^{-1}$. The improvement permitted him later to attempt reciprocal stepping overground with a walker and thus to participate in a study of overground walking training.

$\mathrm{H} 3$ did not show changes as striking as those seen in $\mathrm{H} 1$ and $\mathrm{H} 2$. He did not become capable of taking independent steps during any of his evaluations. His participation in the study was terminated early, at his request. In contrast, $\mathrm{H} 4$ showed considerable change in his stepping ability over the course of the study, as seen in his changes in MTS (see Figure 2). He showed a sharp improvement in MTS in the clonidine evaluation, but changes in stepping pattern for samespeed comparisons were minimal and he remained highly dependent on the harness for support. His inability to tolerate sufficiently long periods of cyproheptadine or baclofen meant that inter-drug comparisons of drug efflect on stepping pattern cannot be made for $\mathrm{H} 4$.

\section{Subjects with limited overground reciprocal walking}

Results in this group of subjects were generally less striking than those seen in the group described above. 
All six of them were able to walk on the treadmill for several minutes at a time with no harness support or manual assistance throughout the study. All of them increased their MTS over the course of their participation in the study, illustrated in Figure 5. Four subjects in this group were able to undergo evaluations for all three drugs, one of whom experienced sharp increases in MTS in association with two of the three drugs. The results for the latter subject, C3, are described in detail.

C3 was referred to the study while taking baclofen and was evaluated three times with no change in his drug status. He showed an increase in MTS from his first evaluation $\left(0.22 \mathrm{~m} \cdot \mathrm{s}^{-1}\right)$ to his second evaluation $\left(0.30 \mathrm{~m} \cdot \mathrm{s}^{-1}\right)$ as seen in the symbols connected by a solid bold line in Figure 5. His MTS remained stable from the second to the third evaluation and then increased following washout of baclofen to $0.34 \mathrm{~m} \cdot \mathrm{s}^{-1}$, and increased again to $0.44 \mathrm{~m} \cdot \mathrm{s}^{-1}$ during

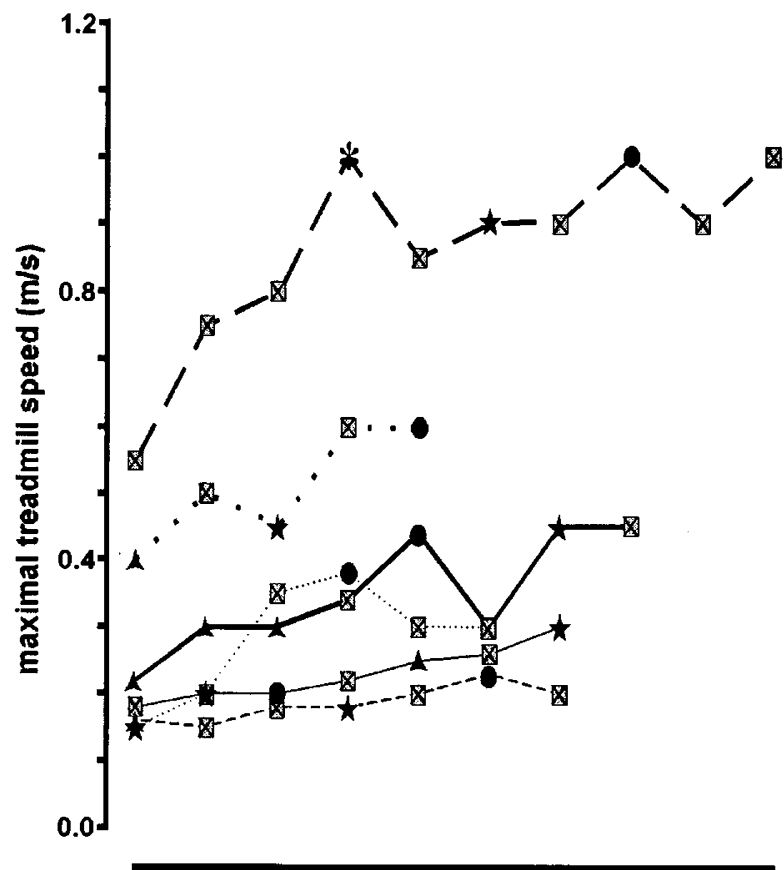

successive evaluations of locomotion

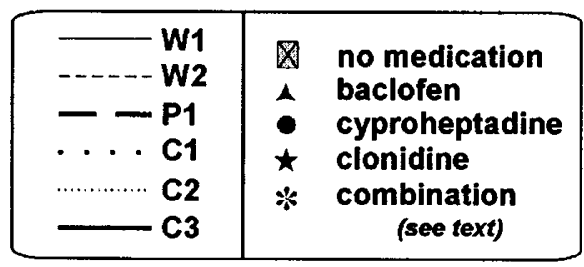

Figure 5 MTS over successive evaluations of locomotion in $\mathrm{W} 1, \mathrm{~W} 2, \mathrm{P} 1, \mathrm{C} 1, \mathrm{C} 2$ and C3. Drug status is reflected by the symbols as indicated in the legend. Each subject's values are linked by a different type of line (see legend). Note that the scale is different from that used in Figure 2 the evaluation for cyproheptadine. His MTS decreased to $0.30 \mathrm{~m} \cdot \mathrm{s}^{-1}$ following washout of cyproheptadine, but increased again to $0.45 \mathrm{~m} \cdot \mathrm{s}^{-1}$ during the evaluation for clonidine. Unlike the post-cyproheptadine washout, his post-clonidine washout evaluation showed no change in MTS from the previous evaluation.

Figure 6 shows EMG data from six evaluations of C3 and Figure 7 shows averaged kinematic data from sequences at $0.20 \mathrm{~m} \cdot \mathrm{s}^{-1}$ from the same six evaluations. The principal differences noted were in the the EMG amplitude of TA, the ankle excursion in swing phase, and the clonus visible in the soleus record in stance phase.

The EMG records for TA are illustrated in the top traces of Figures $6 \mathrm{a}-\mathrm{f}$, inclusive. In the evaluation for baclofen (Figure 6a), the TA amplitude in swing is comparable to its amplitude in stance phase, with no burst of activity. In contrast, in the post-baclofen washout evaluation (Figure 6b) there is a burst of activity in the swing phase in TA. This swing phase EMG burst in TA remains evident in subsequent evaluations (Figures $6 \mathrm{c}-\mathrm{f}$ ). The duration of this TA burst is reduced during the evaluation for clonidine (Figure 6e).

The significance of these changes in TA activity for the ankle excursion can be seen in the averaged ankle excursion records for swing in Figure $7 \mathrm{f}$. During the evaluation for baclofen the swing phase ankle excursion is much more plantarflexed than in any other evaluation, $>20^{\circ}$ more plantarflexed than in any of the washout evaluations. In the evaluation for clonidine, the ankle excursion reverts part way to a more plantarflexed pattern, possibly related to the shorter burst of TA activity in this evaluation.

The other important difference across evaluations for $\mathrm{C} 3$ was in the EMG activity related to ankle clonus. In order to obtain better visualization of EMG activity related to clonus, unaveraged soleus records were used. Figures $6 \mathrm{~g}-1$ shows soleus records from five consecutive cycles of the ten that were used to form the averages shown in Figures $6 \mathrm{a}-\mathrm{f}$. In order to visualize the consistent frequency of clonus, these records have been graphed before normalization and averaging. The individual soleus EMG records for the evaluation for cyproheptadine displayed in Figure $6 \mathrm{i}$ show that activity related to ankle clonus was diminished in comparison with the soleus EMG from all other evaluations (Figure 6g, h, j-1.

In summary, C3 showed changes associated with all three drugs. From the evaluations for baclofen to the subsequent washout evaluation, he showed an improved pattern of ankle excursion and tibialis anterior EMG activation. There was, however, no change in MTS apart from his previously established trend of modest increase. Cyproheptadine was associated with a sharp increase in MTS as well as a reduction in ankle clonus; neither effect was maintained in the subsequent washout period. Clonidine 
was also associated with a sharp increase in MTS that was maintained in the subsequent washout, and with a change in ankle excursion and tibialis anterior EMG activation that was not maintained.

Three other subjects in this group also experienced a reduction in ankle clonus associated with cyproheptadine. W1 had a reduction in clonus activity in soleus with cyproheptadine. Similar to the effect seen in C3, the reduction in clonus was not seen in evaluations for

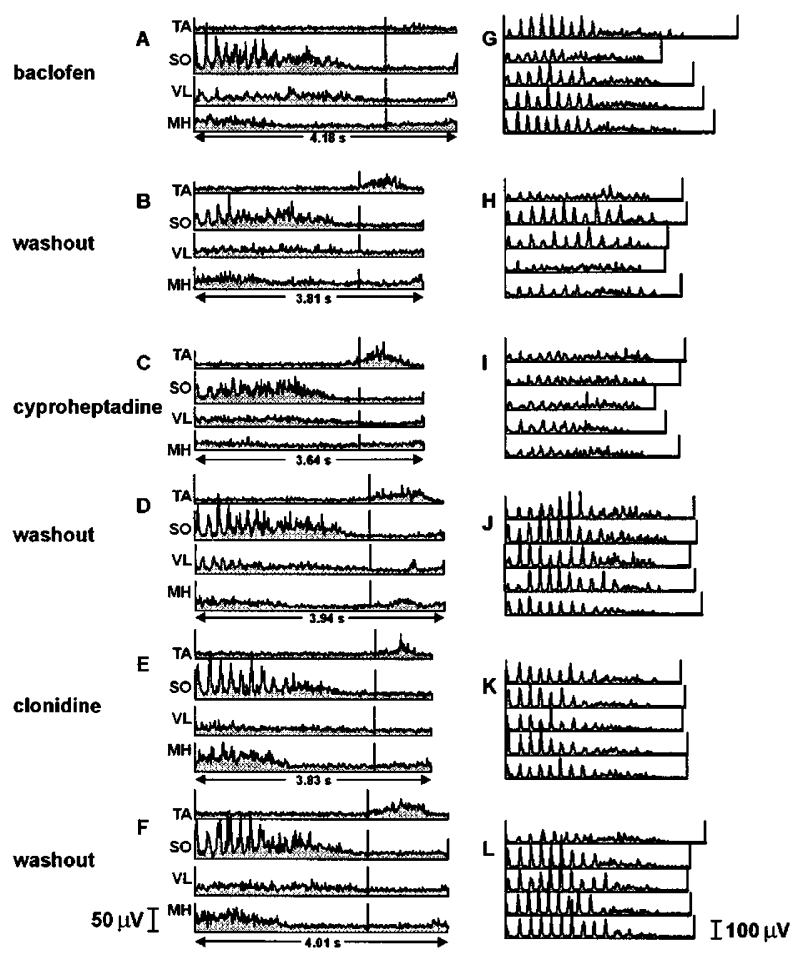

Figure $6 \quad(\mathbf{a}-\mathbf{f})$ Rectified, averaged EMG signal from muscles, of the right leg of $\mathrm{C} 3$ during 10 cycles of treadmill walking. $\mathrm{TA}=$ tibialis anterior; $\mathrm{SO}=$ soleus; $\mathrm{VL}=$ vastus lateralis; $\mathrm{MH}=$ medial hamstrings. Vertical lines indicate stance-swing transition. Averaging was performed separately across stance and swing phases from EMG records from 10 consecutive cycles which had been digitized filtered, full-wave rectified, smoothed and normalized for duration. The two averages were placed side by side, and their lengths adjusted to reflect the average length of the 10 stance and swing phases. The average absolute cycle duration is noted in the figure for each evaluation. All data displayed were gathered during sequences at a treadmill speed of $0.20 \mathrm{~m} / \mathrm{s}$. $(\mathbf{g}-\mathbf{l})$ Rectified, smoothed EMG signals from the right soleus muscle in $\mathrm{C} 3$ during stance period of five of the ten cycles illustrated in $\mathbf{a}-\mathbf{f}$, respectively. Note the different vertical calibration. a,g. Third evaluation while taking baclofen. b,h. Evaluation at the conclusion of washout period after baclofen. c,i. Evaluation during cyproheptadine period. d,j. Evaluation at the conclusion of washout period after cyproheptadine. e,k. Evaluation during clonidine period. f,l Evaluation at the conclusion of washout period after clonidine either of the other drugs or in washout evaluations. W2 and C1 reported a similar effect of reduced ankle clonus in other activities, such as performing transfers and descending stairs.

For the other five subjects in this group, changes in MTS attributable to drugs were not as striking. Two subjects, W1 and W2, the slowest-walking subjects of the group, increased their MTS in an almost linear manner across consecutive evaluations, as seen in the fine solid line and the fine dashed line, respectively, in Figure 5. In two other subjects, $\mathrm{C} 1$ and $\mathrm{C} 2$, the greatest change in MTS occurred following washout of one of the drugs. The two increases in MTS for C1 occurred during washout periods, with a decline in MTS during the clonidine period, and no change in MTS during the cyproheptadine period, seen in the bold dotted line in Figure 5. Nonetheless, C1 reported subjective benefit during the cyproheptadine period. The greatest increase in MTS for C2 occurred following washout of clonidine, with a smaller increase seen during the evaluation for cyproheptadine, seen in the symbols linked by the fine dotted line in Figure 5. The other subject in this group, P1, showed increases in MTS, both at some drug evaluations and at some washout evaluations (bold dashed line in Figure 5).
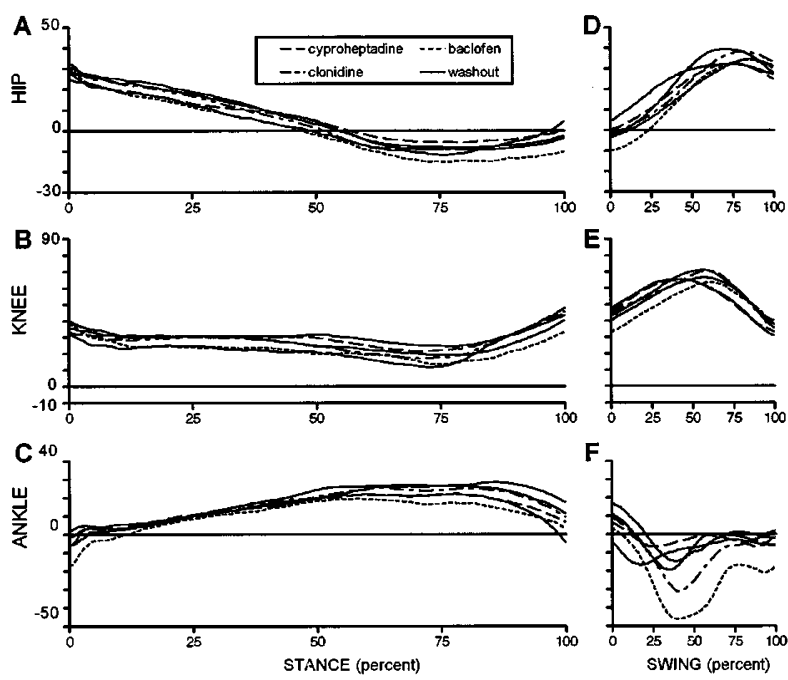

Figure 7 Averaged angular excursions of the right hip $(\mathbf{a}, \mathbf{d})$, knee $(\mathbf{b}, \mathbf{e})$ and ankle $(\mathbf{c}, \mathbf{f})$ of $\mathrm{C} 3$ for stance $(\mathbf{a}, \mathbf{b}, \mathbf{c})$ and swing $(\mathbf{d}, \mathbf{e}, \mathbf{f})$ phases during treadmill walking. Averaging was performed across separately across six stance periods and six swing periods (except for cyproheptadine evaluation and subsequent washout evaluation, 10 stance and swing periods used). The widths of the graphs are proportional to the average stance and swing proportions across all cycles analysed. Solid lines indicate averaged traces for washout evaluations. Broken lines indicated averaged traces for evaluations during drug periods (baclofen: dotted line; cyproheptadine: dashed line; clonidine: dashed-dotted line) 
Subjects with functional overground reciprocal walking In subjects who entered the study with functional overground reciprocal walking, S1 and S2, there were no consistent differences in EMG patterns, kinematic patterns or gait speed in association with changes in drug status. Both of these subjects were capable of treadmill speeds at entry to the study that were substantially higher than the other subjects in the study: $1.0-1.3 \mathrm{~m} \cdot \mathrm{s}^{-1}$.

Summary of speed changes and secondary drug effects Speed changes In Figure 8, the change in MTS has been plotted as a function of the subject's initial MTS for $\mathrm{H} 1, \mathrm{H} 2, \mathrm{H} 4$ and all six of the subjects in the second group. To obtain the change in MTS for each drug, the MTS during the immediately previous period (initial no-drug condition or washout) was subtracted from the MTS during the drug period (Figure 8a, c, e). Cyproheptadine (Figure 8a) was associated with an increase $(\mathrm{H} 1, \mathrm{H} 2, \mathrm{~W} 2, \mathrm{C} 2, \mathrm{C} 3, \mathrm{P} 1)$ or no change (W1,
C1) in MTS. Several of the increases with cyproheptadine represented a large change as a proportion of their initial MTS (H1, H2, C3). Clonidine (Figure 8c) was also associated with increases in MTS (H2, H4, W1, $\mathrm{C} 3$, P1) some of which were large proportional increases $(\mathrm{H} 2, \mathrm{H} 4, \mathrm{C} 3)$. However, clonidine was associated in other subjects with no change (W2) or a decrease $(\mathrm{H} 1, \mathrm{C} 1)$ in MTS. Baclofen (Figure 8e) was associated with a small increase (W1) or no change (H2) in MTS.

The data regarding change in MTS following washout of each drug are equally interesting. To obtain the change in MTS following each drug, the MTS during the immediately previous drug period was subtracted from the MTS during the washout period (Figure 8b, d, f). Cessation of cyproheptadine was never associated with an increase in MTS, but rather with no change $(\mathrm{H} 1, \mathrm{~W} 1)$ or a decrease $(\mathrm{H} 2, \mathrm{~W} 2, \mathrm{C} 2$, $\mathrm{C} 3, \mathrm{P} 1$ ) in MTS (see Figure 8b). In contrast, cessation of clonidine (Figure 8d) or baclofen (Figure 8d) were often associated with an increase in MTS (clonidine:
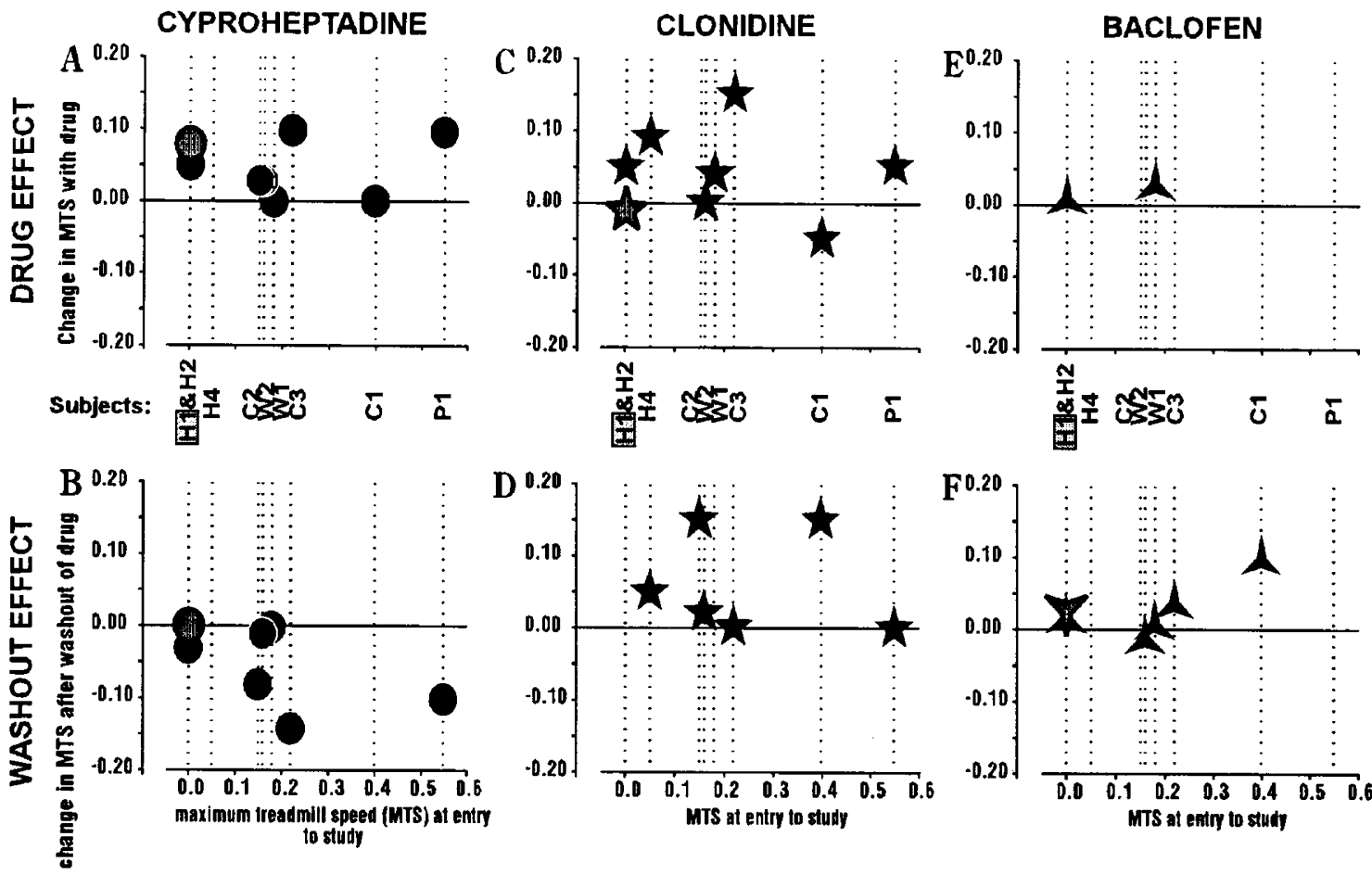

Figure 8 The change in absolute value of MTS is plotted as a function of the subject's initial MTS. In each graph, each vertical dotted line represents a single subject except for the left-most dotted line which represents $\mathrm{H} 1$ and $\mathrm{H} 2$ who both had an initial (unassisted) MTS of zero. See legend for dilferent drug symbols. Data from H4, S1 and S2 have been omitted because they showed no MTS changes in association with change in drug status. $\mathbf{a}, \mathbf{b}$ : cyproheptadine/washout. c, d: clonidine/washout. e, f: baclofen/washout. a, c, e: The change value for each drug has been calculated as the subject's MTS during a drug period minus his MTS during the immediately previous period of no medication. Missing values are due to subject's being unable to complete a drug evaluation (cyproheptadine: H3, H4; baclofen: H3, H4, P1, C2) or to subjects' entering the study while taking a drug (baclofen: H1, W2, C1, and C3; clonidine: C2). b, d, f: The change value for each drug has been calculated as the subject's MTS during a drug period minus his MTS during the immediately subsequent period of no medication. Missing values are due to subjects' being unable to complete a drug evaluation (cyproheptadine: H3, H4; baclofen: H3, H4, P1, C2) or to subjects' discontinuing the study without completing a final washout evaluation (cyproheptadine: $\mathrm{C} 1$; clonidine: H1, H2, W1) 
Table 2 Secondary effects

\begin{tabular}{|c|c|c|}
\hline Clonidine & Subjects & Codes \\
\hline dry mouth & 7 & $\begin{array}{l}\mathrm{H} 1, \mathrm{H} 2, \mathrm{~W} 2, \mathrm{P} 1, \\
\mathrm{C} 3, \mathrm{~S} 1, \mathrm{~S} 2\end{array}$ \\
\hline 个urinary frequency & 4 & $\mathrm{~W} 1, \mathrm{C} 2, \mathrm{~S} 1, \mathrm{~S} 2$ \\
\hline fatiguability/^energy & 4 & $\mathrm{C} 1, \mathrm{~W} 2, \mathrm{P} 1, \mathrm{~S} 2$ \\
\hline light-headedness/dizziness & 4 & $\mathrm{~W} 2, \mathrm{C} 1, \mathrm{C} 3, \mathrm{~S} 2$ \\
\hline constipation & 3 & $\mathrm{C} 2, \mathrm{~S} 1, \mathrm{~S} 2$ \\
\hline$\downarrow_{\text {urinary } \text { urgency }^{1}}$ & 2 & $\mathrm{H} 3, \mathrm{P} 1$ \\
\hline 个appetite & 2 & $\mathrm{C} 1, \mathrm{~S} 2$ \\
\hline numbness & 1 & $\mathrm{P} 1$ \\
\hline altered sexual function $^{2}$ & 1 & $\mathrm{C} 2$ \\
\hline nausea & 1 & $\mathrm{C} 3$ \\
\hline Cyproheptadine & Subjects & Codes \\
\hline 个appetite & 5 & $\mathrm{H} 2, \mathrm{~W} 1, \mathrm{C} 1, \mathrm{C} 3, \mathrm{~S}$ \\
\hline headache/nausea ${ }^{3}$ & 2 & $\mathrm{H} 4, \mathrm{~S} 2$ \\
\hline fatiguability/\energy & 2 & C3, S1 \\
\hline subjective $\downarrow$ in strength & 1 & W1 \\
\hline 个urinary frequency & 1 & $\mathrm{C} 2$ \\
\hline${\text { skin } \operatorname{rash}^{3}}^{3}$ & 1 & \\
\hline baclofen & Subjects & Codes \\
\hline 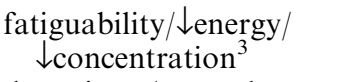 & 3 & $\mathrm{H} 4, \mathrm{P} 1, \mathrm{C} 2$ \\
\hline drowsiness/somnolence & 3 & $\mathrm{~W} 1, \mathrm{P} 1, \mathrm{C} 3$ \\
\hline subjective $\downarrow$ in strength & 2 & $\mathrm{H} 1, \mathrm{C} 3$ \\
\hline$\uparrow$ spasms $^{3}$ & 2 & $\mathrm{H} 4, \mathrm{P} 1$ \\
\hline subjective $\downarrow$ in sensation & 1 & C3 \\
\hline
\end{tabular}

${ }^{1}$ Regarded as a benefit by subjects. ${ }^{2}$ Real incidence may be higher because subjects may be reluctant to discuss. ${ }^{3}$ Cited as (one of) reason(s) for discontinuing drug early and/or dropping out of the study

H4, W2, C1, C2; baclofen: H1, H2, C1, C3) and other times with no change (clonidine: $\mathrm{C} 3, \mathrm{P} 1)$ or a minimal decrease (baclofen: W2) in MTS.

Secondary effects The side effects reported by the subjects are summarized in Table 2 . The list of effects was compiled from effects attributed to the drugs by the subjects, reported either during a drug period or after the subsequent washout.

Clonidine was associated with side effects more often than the other two drugs, in particular the effect of dry mouth. Cyproheptadine was commonly associated with an increase in appetite, unsurprisingly because it has been prescribed in other populations as an appetite stimulant. ${ }^{28,29}$ The most commonly reported side effect during the baclofen period was a feeling of drowsiness or somnolence, consistent with other reports. $^{30,31}$ The side effects of drowsiness and fatiguability with any of the drugs were not visible to the experimenters, nor did they interfere with performing evaluations, except when the drug period could not be completed.

The side effects associated with clonidine were not deleterious enough in any subject to result in drop-out or missing an evaluation. In contrast, cyproheptadine and baclofen were both intolerable to one or more subjects: cyproheptadine principally because of the side effect of headache and nausea, baclofen principally because of a feeling of fatiguability and inability to concentrate. In two subjects, baclofen was associated with a increased occurrence and/or severity of spasms. Both had had experience with baclofen prior to entering the study: $\mathrm{H} 4$ had experienced the same effect at that time, although it had not been as severe; P1 had not previously experienced.

Many subjects elected to continue one or more of the drugs following their participation in the study, despite side effects for some. Both $\mathrm{H} 1$ and $\mathrm{H} 2$ chose to continue a combination of cyproheptadine and clonidine at the conclusion of the study. In particular, they were pleased with cyproheptadine: $\mathrm{H} 1$ because he was able to walk overground for short distances using a rolling walker with forearm supports; and $\mathrm{H} 2$ because he had a marked reduction in night spasms that had been interrupting his sleep. W1 reinstated a low dose of cyproheptadine in order to control ankle clonus. W2 started a combination of cyproheptadine and baclofen to reduce stiffness and spasms. $\mathrm{C} 1$ continued cyproheptadine because of the benefit of reduced stiffness and spasms. C3 chose a combination of cyproheptadine and clonidine because he had experienced benefit during both of those periods. S1 reported that during the clonidine period he was able to attempt jogging and jumping. He chose to continue clonidine following his participation in the study.

In summary, only one subject (W2) elected to continue baclofen after participating in the study, in combination with cyproheptadine. Six subjects elected to continue cyproheptadine, alone or in combination with another drug, and four subjects elected to continue clonidine, alone or in combination with another drug. In all cases of continuing drug therapy, the subjects continued them for at least several months and in some cases for over a year. Three subjects $(\mathrm{H} 2, \mathrm{~W} 1$ and $\mathrm{W} 2)$ subsequently entered a study of the effects of functional electrical stimulation (FES) and training on walking, and they continued a stable dose of drug(s) from the present study into the FES study. It is believed that $\mathrm{H} 2$ would not have been able to participate in the FES study, and that the other two would have had more difficulty participating, without the continuing drug therapy.

\section{Discussion}

In this comparison of the effects of clonidine, cyproheptadine and baclofen on walking in SCI subjects with chronic incomplete lesions, we found that the drugs have different effects, most noticeably in subjects with greater neurological impairment. For clonidine, the effects included longer cycles, increased treadmill speed and more upright posture. These changes were similar to those seen in chronic spinal cats who had been trained to walk post-transection, had subsequently shown a deterioration in locomotor 
pattern and were then injected with clonidine. ${ }^{32}$ For cyproheptadine, the effects included the striking emergence of an ability to perform continuous treadmill stepping without manual assistance in two subjects. This resembles the re-emergence of rhythmic stepping in chronic spinal cats upon cyproheptadine injection after their locomotor pattern had been disrupted by injection of serotonergic precursor or agonists. ${ }^{33}$ Cyproheptadine was also associated with increased treadmill speed and reduced ankle clonus. The reduction in clonus was greater with cyproheptadine than with the other two drugs and it did not persist following washout, unlike some of the other drug effects. In contrast to the other two drugs, baclofen was associated with little effect on walking pattern in any of the subjects, regardless of the extent of impairment, although they reported that it reduced their spasticity. In their walking patterns, there were changes in EMG amplitude but minimal change in overall timing; these were not linked with functional changes except for the example of a reduction in abnormal ankle plantarflexion and improved activation of the tibialis anterior muscle in swing phase following washout of baclofen. These results may be linked with the observations of increased paw drag with decreased reflex responses in chronic spinal cats with baclofen. ${ }^{34}$ However, we did not find other deficits with baclofen that parallel the findings with baclofen in chronic spinal cats such as reduced weight support of the hindquarters and arrest of walking with higher doses. ${ }^{34}$

The finding that subjects with relatively greater neurological impairment benefit most from cyproheptadine and clonidine is consistent with previous studies. $^{12-14}$ In previous studies of clonidine versus placebo, ${ }^{14,35}$ subjects comparable to the more disabled subjects in the present study showed greater improvements in walking ability following oral or intrathecal clonidine. Subjects who had already regained functional overground walking showed little effect of clonidine. ${ }^{14}$ Similarly, in a study of cyproheptadine versus placebo, ${ }^{13}$ subjects with greater neurological impairment showed greater improvement with cyproheptadine than did those subjects who had previously regained functional overground walking.

Although oral baclofen has been in clinical use for many years, there has been remarkably little investigation of its effects on walking. There has been a recent increase in published reports of baclofen's effects, largely because of the development of intrathecal modes of delivery. However, even when this literature is considered, reports of baclofen's effects on walking are scarce, and consist mostly of anecdotal reports or rating on an ordinal scale $17,36-45$ (for review, see reference 46). In addition, the time course of the changes was often long enough for many other factors to have influenced walking ability. One exception was a report of a comparison of oral baclofen and DS103282 (tizanidine) on the walking pattern of spastic paretic subjects. Greater mean ankle dorsiflexion was seen during baclofen treatment than during tizanidine treatment. However, the pattern during baclofen was not significantly different from the pattern before treatment or during placebo treatment. Thus, only minimal objective and subjective changes in gait were found with baclofen or tizanidine. ${ }^{47}$ These conclusions regarding baclofen seem generally borne out by our findings.

Although the primary purpose of this study was to compare the effects of the three drugs during short periods of drug administration, we were also able to observe the changes in walking over a series of evaluations and the extent of retention of changes in walking. Two findings particularly merit further discussion. The first is that, as exemplified by the data illustrated in Figure 8, there appear to be differences among the drugs regarding the subjects' ability to walk following washout of the drug. Specifically, the washout of cyproheptadine frequently led to a reduction of MTS in subjects who had previously shown an increase or no change in MTS, whereas the washout of clonidine frequently led to a maintenance or increase of MTS. The reasons for the differences are unclear. However, the clonidine results are consistent with the findings in acute spinal cats that clonidine injections combined with interactive training lead to rapid recovery of walking that is retained following cessation of clonidine injections. ${ }^{48,49}$ The observation that cyproheptadine washout more frequently led to a reduction in MTS suggests that its effect, at least in those cases, was based on a shortterm change in spinal cord functioning that was not well sustained upon drug washout (see section on Possible mechanisms, below). The second important finding for discussion is the overall increase in walking ability as best exemplified by the increase in MTS shown in the majority of subjects (see Figures 2 and $5)$. The subjects who showed the greatest change were those who, at entry to the study, could produce limited movement of the lower limbs on the treadmill. It is to this subpopulation of SCI persons that future research regarding drug effiects should be targeted.

\section{Possible mechanisms of drug effects}

There are several mechanisms by which the subjects may have increased their walking abilities during the course of the drug trial, including (1) stimulation of receptors in the spinal cord by the drugs themselves, (2) plastic changes in the central nervous system, and (3) improvements in muscular and/or cardiovascular fitness. In regard to the first mechanism, it is clear from studies of animals with spinal cord transections that all three of clonidine, cyproheptadine and baclofen are able to stimulate receptors within the spinal cord. When there has been an incomplete transection, such as was the case for subjects in this study, the drugs stimulate both presynaptic and post-synaptic receptors. Some of the heterogeneity of drug response may be attributable to a different distribution of injury of descending pathways and consequently a different degree of change in the 
sensitivity of different pre-and post-synaptic receptors. The heterogeneity of drug response may also be explained by the different roles of these drugs and their associated transmitter systems in the generation and modulation of locomotion and in the modulation of reflexes. All three of clonidine, cyproheptadine and baclofen have been associated with reduced reflex responses both in spinal animals ${ }^{33,50-52}$ as well as in SCI humans. ${ }^{53-58}$ However, the three drugs modulate locomotion differently, suggesting that the relationship between modulation of reflexes and modulation of locomotion requires further investigation.

It is well-established that there are circuits in the spinal cord of most vertebrates that are capable of generating rhythmic patterns, including those of locomotor patterns. ${ }^{59,60}$ However, the limited recovery of locomotion in primates ${ }^{61}$ has been suggested as evidence that the circuitry is different in primates and may preclude recovery of walking. More recently, it has been suggested that some macaque monkeys may recover locomotion after severe incomplete lesions of the spinal $\operatorname{cord}^{62}$ and that fictive locomotion may be induced in marmosets. ${ }^{63}$ Furthermore, there is evidence that some elements of spinal rhythmgenerating circuits exist in humans. ${ }^{64-67}$ For example, Calancie and colleagues have reported a case of a subject with severe incomplete spinal cord injury who demonstrated sustained bilateral involuntary motor patterns resembling a walking pattern 17 years postinjury. ${ }^{66}$

In view of the evidence suggesting that there are rhythmic-pattern-generating circuits in the human spinal cord, it is important to investigate whether drugs that modulate locomotion in spinal animals can similarly modulate locomotion in SCI humans. Clonidine has also been associated with initiation of locomotion in spinal-cord-transected animals, as well as with modulation of a locomotor pattern that has been brought about by interactive training posttransection. ${ }^{48-50}$ The mechanisms whereby the cats' locomotion was changed may also contribute to the effects seen in the human SCI subjects. Cyproheptadine has been associated with restitution of a rhythmic locomotor pattern in previously trained spinal animals, after the locomotor pattern has been disrupted by application of serotonergic agonists or precursors. ${ }^{33}$ By this rationale it may thus be effective in improving walking in human SCI subjects but only if their deficits are at least partly related to hypersensitivity or other changes in the serotonergic receptors of the spinal cord. Denervation supersensitivity of serotonergic receptors has been demonstrated in spinalized rats. ${ }^{68}$ The withdrawal of cyproheptadine's blocking of serotonergic receptors in such a case would presumably result in a return of the walking deficits if the underlying changes in the serotonergic receptors remained unchanged. Unlike the other two drugs, baclofen has not been linked to improved locomotion in spinal animals, nor have any other drugs that stimulate GABA receptors.
The second possible mechanism is that of plastic changes in the central nervous system. The period of spontaneous recovery following spinal cord injury is believed to last approximately one year, and measurements of neurological impairment show little change after the first year post-injury. ${ }^{18,19}$ However, the usual clinical means of measuring muscle and sensory functions are not sensitive to small changes, and in addition, most of the literature pertains to clinically complete injuries rather than the incomplete injuries that affected the subjects in this study. Furthermore, a lack of change in conventional clinical muscle or sensory testing does not preclude ongoing plasticity in the preserved pathways that coordinate movement. There is substantial evidence of plastic changes in the spinal cord, both of monosynaptic pathways such as the stretch reflex ${ }^{69-71}$ and the H-reflex ${ }^{72,73}$ and of polysynaptic pathways such as in the differing abilities in stance-trained versus stepping-trained spinal cats. ${ }^{74,75}$ The importance of stepping or locomotor training in the recovery of walking after spinal cord injury or transection has been emphasized by several research groups. ${ }^{74-79}$ This has led to research by numerous groups into the benefits of locomotor training for SCI subjects. ${ }^{80-84}$ It seems clear that the recovery of walking may be enhanced by such training, even in cases of relatively severe injury. For the present study, the evaluations of walking were conducted every 2-3 weeks, as compared with training protocols in which training is conducted generally five times per week, and thus we did not expect a training effect. However, the improvement in some subjects with no major drug effects, and the finding that most subjects could follow higher treadmill speeds by the end of the study suggest that training effects may have contributed to the results.

The third area of possible mechanisms is that there may have been improved muscular and/or cardiovascular fitness. Although the subjects were similar in age, general health, type of injury (ie traumatic) and duration since injury, their differing degrees of disability from spinal cord injury resulted in intersubject variability in muscle strength and endurance and in overall fitness. For the subjects who could not walk overground, the locomotor evaluations may have constituted a relatively rare opportunity to exercise the lower limb muscles and obtain an overall fitness benefit, in contrast to the less disabled subjects who walked overground to varying degrees. This difference may have contributed to the finding that more disabled subjects showed proportionally greater change in walking ability.

\section{Implications for future research}

The first principal implication for future research is that the type of SCI subjects that seem most likely to improve with drugs are those whose injuries have resulted in severe but not total loss of lower limb motor function: i.e. those who retained some ability to 
move their lower limbs but who have very limited or no ability to walk overground. The inclusion of subjects whose walking ability is already substantially recovered yielded less interesting results. We may speculate that their extent of spinal cord change, in particular the distribution of damage to descending pathways including monoaminergic pathways, was not sufficient for the drugs to be beneficial for walking in those subjects.

The second principal implication is that experience with evaluations of walking may constitute a form of training, especially in some cases after drug effects have increased the subjects' ability to take steps. In light of this, as well as in light of findings in spinal animals, future research regarding drug effects on walking should incorporate controlled training protocols so as to compare appropriately the potential effects of the drugs, and to maximize the benefit that may be conferred on people with spinal cord injury.

The third principal implication is that clonidine, cyproheptadine and baclofen, which are all able to modulate reflexes, have different modulatory effects on locomotion. The relationship between modulation of reflexes and modulation of locomotion will need further exploration to determine which pharmacological treatments are optimal and what factors determine a beneficial treatment response in people with incomplete spinal cord injury.

\section{Acknowledgements}

The project was supported by the Neuroscience Network of Canada (NNC). KEN received studentship support from the Rick Hansen Man in Motion Legacy Fund and from the NNC. AP received studentship support from the Fonds pour la formation de chercheurs et l'aide á la recherche. $\mathrm{HB}$ is a chercheur-boursier of the Fonds de la recherche en santé du Québec.

We thank the subjects for their participation, and the physicians who referred them, in particular Dr R Beaupré of Québec. We thank M Ladouceur in particular, as well as A Alfath, M Appelby, G Bossé, S Carrier, S Chambers, L Chilco, K Chitre, L Glasa, M Kilfoil, SM Poon and S Séguin for laboratory assistance. We also thank Dr S Rossignol for comments on a previous draft of the manuscript.

\section{References}

1 Stover SL, Fine PB, eds. Spinal Cord Injury: The Facts and Figures. Birmingham, Alabama: The University of Alabama at Birmingham, 1986.

2 Tator $\mathrm{CH}$ et al. Changes in epidemiology of acute spinal cord injury from 1947 to 1981. Surg Neurol 1993; 40: 207-215.

3 Dixon GS, Danesh JN, Caradoc-Davies TH. Epidemiology of spinal cord injury in New Zealand. Neuroepidemiology 1993; 12: $88-95$.

4 Knutsdottir S. Spinal cord injuries in Iceland 1973-1989. A follow up study. Paraplegia 1993; 31: 68-72.
5 Shingu $\mathrm{H}$ et al. A nationwide epidemiological survey of spinal cord injuries in Japan from January 1990 to December 1992. Paraplegia 1995; 33: $183-188$.

6 Silberstein B, Rabinovich S. Epidemiology of spinal cord injuries in Novosibirsk, Russia. Paraplegia 1995; 33: 322-325.

7 Knutsson E, Richards CL. Different types of disturbed motor control in gait of hemiparetic patients. Brain 1979; 102: $405-430$.

8 Dietz V, Quintern J, Berger W. Electrophysiological studies of gait in spasticity and rigidity: evidence that altered mechanical properties of muscle contribute to hypertonia. Brain 1981; 104: $431-449$.

9 Conrad B, Benecke R, Meinck H-M. Gait disturbances in paraspastic patients. In: Delwaide PJ, Young M (eds.) Clinical Neurophysiology in Spasticity. Contribution to Assessment and Pathophysiology. Amsterdam: Elsevier, 1985; pp 55-174.

10 Fung J, Barbeau H. A dynamic EMG profile to quantify muscular activation disorder in spastic paretic gait. Electroencephalogr Clin Neurophysiol 1989; 73: 233-244.

11 Kerrigan DC, Gronley J, Perry J. Stiff-legged gait in spastic paresis. Am J Phys Med Rehabil 1991; 70: 294-300.

12 Fung J, Stewart JE, Barbeau H. The combined effects of clonidine and cyproheptadine with interactive training on the modulation of locomotion in spinal cord injured subjects. $J$ Neurol Sci 1990; 100: 85-93.

13 Wainberg M, Barbeau H, Gauthier S. The effects of cyproheptadine on locomotion and on spasticity in patients with spinal cord injuries. J Neurol Neurosurg Psychiatry 1990; 53: 754-763.

14 Stewart JE, Barbeau H, Gauthier S. Modulation of locomotor patterns and spasticity with clonidine in spinal cord injured patients. Can J Neurol Sci 1991; 18: 321 -332.

15 Dietz V, Colombo G, Jensen L, Baumgartner L. Locomotor capacity of spinal cord in paraplegic patients. Ann Neurol 1995; 37: $574-582$.

16 Parke B, Penn RD, Savoy SM, Corcos DM. Functional outcome after delivery of intrathecal baclofen. Arch Phys Med Rehabil 1989; 70: $30-32$.

17 Azouvi $\mathrm{P}$ et al. Intrathecal baclofen administration for control of severe spinal spasticity: functional improvement and long-term follow-up. Arch Phys Med Rehabil 1996; 77: 35-39.

18 Piepmeier JM, Jenkins NR. Late neurological changes following traumatic spinal cord injury. J Neurosurg 1988; 69: $399-402$.

19 Ditunno JF Jr, Stover SL, Freed MM, Ahn JH. Motor recovery of the upper extremities in traumatic quadriplegia: a multicenter study. Arch Phys Med Rehabil 1992; 73: 431 - 436.

20 Norman, KE, Barbeau H. Comparison of the effects of cyproheptadine, clonidine and baclofen on locomotor pattern in individual subjects with spastic paresis. Soc Neurosci Abstr; $1992,860$.

21 Norman KE, Barbeau H. Comparison of cyproheptadine, clonidine and baclofen on the modulation of gait pattern in subjects with spinal cord injury. In: Thilmann AF, Burke DJ, Rymer WZ, eds. Spasticity: Mechanisms and Management. Berlin: Springer-Verlag, 1993: pp 410-425.

22 Norman KE, Barbeau H. Comparison of the effects of cyproheptadine, clonidine and baclofen on gait pattern in subjects with spastic paresis. Can J Rehab 1993; 7: 219-220.

23 Barbeau H, Wainberg M, Finch L. Description and application of a system for locomotor rehabilitation. Med Biol Eng Comput 1987; 25: $341-344$.

24 Norman KE, Pepin A, Ladouceur M, Barbeau H. A treadmill apparatus and harness support for evaluation and rehabilitation of gait. Arch Phys Med Rehabil 1995; 76: 772-778.

25 Finch L, Barbeau H, Arsenault BA. Influence of body weight support on normal human gait: development of a gait retraining strategy. Phys Ther 1991; 71: $842-856$.

26 Nilsson J, Thorstensson A, Halbertsma J. Changes in leg movements and muscle activity with speed of locomotion and mode of progression in humans. Acta Physiol Scand 1985; 123: $457-475$.

27 Winter DA. Biomechanical motor patterns in normal walking. $J$ Motor Behav 1983; 15: 302-330. 
28 Saleh JW, Yang MU, van Itallie TB, Hashim SA. Ingestive behavior and composition of weight change during cyproheptadine administration. Int J Obes 1979; 3: 213-221.

29 Kardinal CG et al. A controlled trial of cyproheptadine in cancer patients with anorexia and/or cachexia. Cancer 1990; 65: $2657-$ 2662.

30 Young RR, Delwaide PJ. Drug therapy. Spasticity. $N$ Eng J Med 1981; 304: $28-33,96-99$

31 Whyte J, Robinson KM. Pharmacologic management. In: Glenn MB, Whyte J, (eds.) The Practical Management of Spasticity in Children and Adults. Malvern, Pennsylvania: Lea \& Febiger; 1990 pp $201-226$.

32 Rossignol S, Chau C, Barbeau H. Pharmacology of locomotion in chronic spinal cats. In: Taylor A, Gladden MH, Durbaba R, (eds.) Alpha and Gamma Motor Systems. New York: Plenum Press, 1996 pp $449-455$.

33 Barbeau H, Rossignol S. The effects of serotonergic drugs on the locomotor pattern and on cutaneous reflexes of the adult chronic spinal cat. Brain Res 1990; 514: 55-67.

34 Chau $\mathrm{C}$ et al. Effects of GABAergic drugs on locomotion in adult chronic spinal cats. Soc Neurosci Abstr; 1995: 420

35 Rémy-Neris $\mathrm{O}$ et al. The effects of intrathecal clonidine on spinal reflexes and on locomotion in incomplete paraplegic subjects. Abstracts from 2nd Meeting of European Neuroscience, 1996.

36 Broseta $\mathbf{J}$ et al. Use of intrathecal baclofen administered by programmable infusion pumps in resistant spasticity. Acta Neurochir Suppl 1989; 46: $39-45$.

37 Lazorthes $\mathrm{Y}$ et al. Chronic intrathecal baclofen administration for control of severe spasticity. J Neurosurg 1990; 72: 393-402.

38 Penn RD. Intrathecal baclofen for severe spasticity. Ann NY Acad Sci 1988; 531: $157-166$.

39 Latash ML, Penn RD, Corcos DM, Gottlieb GL. Effects of intrathecal baclofen on voluntary motor control in spastic paresis. J Neurosurg 1990; 72: 388-392.

40 Loubser PG et al. Continuous infusion of intrathecal baclofen: long-term effects on spasticity in spinal cord injury. Paraplegic 1991; 29: $48-64$

41 Sahuquillo $\mathbf{J}$ et al. Intraspinal baclofen in the treatment of severe spasticity and spasms. Acta Neurochir (Wien) 1991; 110: 166 173.

42 Saltuari L et al. Indication, efficiency and complications of intrathecal pump supported baclofen treatment in spinal spasticity. Acta Neurol (Napoli) 1992; 14: 187-194.

43 Meythaler JM et al. Intrathecal baclofen in hereditary spastic paraparesis. Arch Phys Med Rehabil 1992; 73: 794-797.

44 Ochs GA. Intrathecal baclofen. Baillères Clin Neurol 1993; 2: $73-86$.

45 Abel NA, Smith RA. Intrathecal baclofen for treatment of intractable spinal spasticity. Arch Phys Med Rehabil 1994; 75: $54-58$.

46 Campbell SK, Almeida GL, Penn RD, Corcos DM. The effects of intrathecally administered baclofen on function in patients with spasticity. Phys Ther 1995; 75: 352-362.

47 Corston RN, Johnson F, Godwin-Austen RB. The assessment of drug treatment of spastic gait. J Neurol Neurosurg Psychiatry 1981; 44: $1035-1039$.

48 Barbeau H, Chau C, Rossignol S. Noradrenergic agonists and locomotor training affect locomotor recovery after cord transection in adult cats. Brain Res Bull 1993; 30: 387-393.

49 Chau C, Barbeau H, Rossignol S. Early locomotor training with clonidine in spinal cats. J Neurophysiol 1998; 79: $392-409$.

50 Barbeau H, Julien C, Rossignol S. The effects of clonidine and yohimbine on locomotion and cutaneous reflexes in the adult chronic spinal cat. Brain Res 1987; 437: 83-96.

51 Davidoff RA, Sears S. The effects of Lioresal on synaptic activity in the isolated spinal cord. Neurology 1974; 24: 957-963.

52 Fox $\mathrm{S}$ et al. Action of baclofen on mammalian synaptic transmission. Neuroscience 1978; 3: 495-515.

53 Tuckman J, Chu DS, Petrillo CR, Naftchi NE. Clinical trial of an alpha adrenergic receptor stimulating drug (clonidine) for treatment of spasticity in spinal cord injured patients. In: Naftchi NE, (ed.) Spinal Cord Injury. New York: SP Medicine \& Science Books, 1982; pp 133-137.
54 Donovan YM, Carter RE, Rossi CD, Wilkerson MA. Clonidine effect on spasticity: a clinical trial. Arch Phys Med Rehabil 1988; 69: $193-194$.

55 Barbeau H, Richards CL, Bédard PJ. Action of cyproheptadine in spastic paraparetic patients. J Neurol Neurosurg Psychiatry 1982; 45: 923 - 926.

56 Duncan GW, Shahani BT, Young RR. An evaluation of baclofen treatment for certain symptoms in patients with spinal cord lesions. Neurology 1976; 26: $441-446$.

57 Sachais BA, Logue JN, Carey MS. Baclofen, a new antispastic drug. A controlled, multicenter trial in patients with multiple sclerosis. Arch Neurol 1977; 34: $422-428$.

58 Nance PW. A comparison of clonidine, cyproheptadine and baclofen in spastic spinal cord injured patients. J Am Paraplegia Soc 1994; 17: 150-156.

59 Grillner S. Control of locomotion in bipeds, tetrapods and fish. In: Brooks VB, (ed.) Handbook of Physiology, Section 1: The Nervous System, Volume II. Motor control. Bethesda, Maryland: American Physiological Society, 1981: pp 1179-1236.

60 Rossignol S. Neural control of stereotypic limb movements. In: Rowell LB, Shepherd JT, (eds.) Handbook of Physiology, Section 12. Exercise: Regulation and Integration of Multiple Systems. Bethesda, Maryland: American Physiological Society, 1996: pp $173-216$.

61 Eidelberg E, Walden JG, Nguyen LH. Locomotor control in macaque monkeys. Brain 1981; 104: 647-663.

62 Vilensky JA, Moore AM, Eidelberg E, Walden JG. Recovery of locomotion in monkeys with spinal cord lesions. J Motor Behav 1992; 24: $288-296$

63 Hultborn H, Petersen N, Brownstone R, Nielsen J. Evidence of fictive spinal locomotion in the marmoset (callithrix jacchus). Soc Neurosci Abstr 1993: 539

64 Bussel B et al. Myoclonus in a patient with spinal cord transection. Possible involvement of the spinal stepping generator. Brain 1988; 111: $1235-1245$.

65 Bussel B, Roby-Brami A, Rémy-Néris O, Yakovleff A. Evidence for a spinal stepping generator in man. Paraplegia 1996; 34: 91 92.

66 Calancie B et al. Involuntary stepping after chronic spinal cord injury: evidence for a central rhythm generator for locomotion in man. Brain 1994; 117: 1143 - 1159.

67 Illis LS. Is there a central pattern generator in man? Paraplegia 1995; 33: 239 - 240 .

68 Barbeau H, Bédard PJ. Denervation supersensitivity to 5hydroxytryptophan in rats following spinal transection and 5,7dihydroxytryptamine injection. Neuropharmacology 1981; 20: $611-616$.

69 Wolpaw JR et al. Adaptive plasticity in the spinal stretch reflex. Brain Res 1983; 267: 196-200.

70 Wolpaw JR. Adaptive plasticity in the spinal stretch reflex: reversal and re-development. Brain Res 1983; 278: 299-304.

71 Wolpaw JR, Braitman DJ, Seegal RF. Adaptive plasticity in the spinal stretch reflex: initial development. $J$ Neurophysiol 1983; 50: $1296-1311$.

72 Wolpaw JR. Operant conditioning of primate spinal reflexes: the H-reflex. J Neurophysiol 1987; 57: $443-459$.

73 Wolpaw JR, Lee CL, Calaitges JG. Operant conditioning of primate triceps surae H-reflex produces reflex asymmetry. Exp Brain Res 1989; 75: 35-39.

74 Edgerton VR et al. Use-dependent plasticity in spinal stepping and standing. Adv Neurol 1997; 72: $233-247$.

75 Edgerton W et al. Does motor learning occur in the spinal cord? Neuroscientist 1997; 3: 287-294.

76 Barbeau H, Rossignol S. Recovery of locomotion after chronic spinalization in the adult cat. Brain Res $1987 ; \mathbf{4 1 2}$ : $84-95$

77 Lovely RG, Gregor RJ, Roy RR, Edgerton VR. Effects of training on the recovery of full-weight bearing stepping in the adult spinal cat. Exp Neurol 1986; 92: $421-435$.

78 Bélanger M, Drew T, Provencher J, Rossignol S. A comparison of treadmill locomotion in adult cats before and after spinal transection. J Neurophysiol 1996; 76: $471-491$. 
79 Muir GD, Steeves M. Sensorimotor stimulation to improve locomotor recovery after spinal cord injury. Trends Neurosci 1997; 20: $72-77$.

80 Wernig A, Müller S. Lauffland locomotion with body weight support improved walking in persons with severe spinal cord injuries. Paraplegia 1992; 30: 229-238.

81 Barbeau H, Danakas M, Arsenault B. The effects of locomotor training in spinal cord injured subjects - A preliminary study. Restor Neurol Neurosci 1993; 5: $81-84$.
82 Dietz V, Colombo G, Jensen L, Baumgartner L. Locomotor capacity of spinal cord in paraplegic patients. Ann Neurol 1995, 37: $574-582$.

83 Barbeau H, Rossignol S. Enhancement of locomotor recovery following spinal cord injury. Curr Opin Neurol 1994; 7: 517-524.

84 Dietz V, Wirz M, Jensen L. Locomotion in patients with spinal cord injuries. Phys Ther 1997; 77: $508-516$. 